\title{
Reflections on our Computer Software Intellectual Property Protection
}

\author{
Shan WU1, a \\ ${ }^{1}$ North China Electric Power University of Bao Ding city in He Bei Province, China \\ a460973737@qq.com
}

\begin{abstract}
Keywords: Computer software, Intellectual property, Protection.
\end{abstract}
\begin{abstract}
The computer software is an important support of modern science and technology, and also, is an important symbol of a country's technological level and core competitiveness, computer software produced to make people more and more attention to its value, but also aware of the need provide legal protection for software, so choose what kind of ways to protect so that the software can be applied better is become the most important issue to be considered. This paper is aimed at the status of existing intellectual property protection, then analyze which the problems in-depth, and accordingly proposes the policies and measures to strengthen intellectual property protection for computer software.
\end{abstract}

\section{Status of computer software intellectual property protection}

In 1959 the United States appeared in the first independent software companies, the term "computer software" came into being, referred to software ; 1978, WIPO published the " Model Regulations on Protection of Computer Software," the computer software is defined as: " computer software, including programs, the program, the program guide three elements computer Software Protection Regulations " China promulgated the definition of computer software are as follows: ." so-called computer software refers to computer programs and related documentation . "

With the extensive application of computer technology in all aspects of social life, computer software has become increasingly important over the significance of intellectual property. This reflects the individual's right to respect and encourage the body, and therefore, since the 1970s, the world will continue into the scope of the legal protection of computer software, and computer software in order to protect and encourage investment and innovation. November in 1972, the Philippines will be the first computer software included in the scope of protection of copyright law. In 1980, the U.S. Copyright Act is amended to clearly defined computer programs as long as the original, belongs to the scope of protection of the Copyright Act of the Uruguay Round of GATT. 1994 signed the "Agreement on Trade-Related Intellectual Property Rights" (referred to as "TRIPS Agreement), will be included in the scope of protection of computer programs. to 2003 , there were already more than 60 countries and regions in the legal protection of computer programs into the copyright system, China is no exception in our country, " copyright Law" explicitly third paragraph 8 computer software included in the classification given protection works ; expressly provided for protection of computer software, computer programs and related documentation are protected by copyright objects of the "Computer Software protection Regulations" computer program , including source and target program source. one that can not recognize artificial recognition and its procedures, refer to the target program source code can be compiled by the machine after its recognition procedures . provisions "Software Ordinance," the source and target text of the same program as the same work . " software regulations "At the same provisions for the protection of the software can not be extended to the development of software used to ideas, concepts, discoveries, principles , algorithms, processing methods and operations in our country," the protection of the general subject matter of the Copyright Law "stipulates that the author lifetime and 50 years after death later, but the " software regulations" computer software to make special provisions, provisions for the protection of both the software for 25 years, before the expiration of the right holder may apply for an extension of 25 years, but no more than 50 years in addition to such " copyright "Computer software copyright registration" "Copyright administrative Punishment implementation Measures " and other computer software intellectual property to be protected Act 
implementing regulations. "

Although the legislative system in our country is the "Copyright Law" as the main way to protect intellectual property rights of computer software, but our " Patent Law " also did not exclude protection for software. Although China patent protection for computer software is not reflected in the "Patent Law" and its related ordinance, but which can still be summed up patent protection for computer software. According to Article II, paragraph "People's Republic of China Patent Law Implementing Rules " , the alleged invention Patent Law means any new technical solution to a product, process or improvement thereof. Review of the provisions of the patent "Review Guidelines " in Chapter 9," a number of provisions concerning patent application relates to a computer program to review the invention ," pointed out : The invention relates to a computer program to solve the problem is the proposed invention, all or part of a process or computer program processes based on the above-described processes performed by a computer program prepared by a computer, the computer object inside the external object or control or treatment solution. In other words, the invention relates to a computer program constitutes a patent application as long as the technical solution in the above sense is the object of the present patent protection.

\section{Problems in Intellectual Property Protection of Computer Software}

In the international protection of computer software copyright law already occupy the mainstream position in China as well. Although copyright law protection software has unique advantages, but, after all, and traditional software works there are important differences in many ways, making it impossible to complete the legal protection of copyright law into the field, in practice, on the performance of this kind to copyright protection Act based model various defects exist, these defects mainly in the following aspects:

The first is the limited scope of copyright protection. Copyright protection for computer software, the biggest loophole in the protection of its object is "thinking and objective manifestations of things, rather than thinking and objective things themselves." China's "Computer Software Protection Regulations," Article VI:. " This Ordinance software copyright protection does not extend to the development of software used in thinking processes, methods of operation or mathematical concepts as such can be seen under the copyright framework law only protects the expression of the software used to develop software without the protection of ideas, processes , methods of operation or mathematical concepts as such, but this software works, ideological, functional objects both functional is the most valuable part, the performance of its value through its use as a community to create economic value, but still, for the protection of software copyright law concept, design and functionality of the powerless, even against illegal copying of copyright works, but it can not prohibit the use of the work described approach to operations, from this point of view, the scope of protection of traditional copyright law to the owner of the computer software would be too narrow. Followed by a period of protection problems. According to China's "Copyright Law", the term of protection of copyright is generally 50 years . Copyright protection software for 25 years, but the author can apply for renewal before the expiry of 25 years. Different from the traditional literary works, a major feature of the software is the high rate of elimination, update speed. Such a long period of protection will only hinder the development of innovative software and detrimental to the public interest.

The third copy is considered copyright protection only, unlike patent protection that protects the use of the software. Copyright Act to allow others to "fair use" and does not constitute infringement. In fact, the software is only in order to create value for society when in use, but also the interests of software developers through the use of software to achieve. If only against illegal copying is prohibited without the illegal use, then the rights of software developers would not be adequately protected.

The fourth is the infringement of the copyright law provides sanctions too light. The main sanction copyright infringement is a civil damages, rarely involving criminal law, and this is consistent with the work of non- usability of the ordinary. But the software copying easy and low cost, and the software tools of their economic value is extremely high, the issue of illegal copying 
lucrative. And these light punitive measures would not achieve the appropriate action.

Copyright protection software has achieved a dominant position, but because of the increasingly apparent shortcomings of copyright protection, patent protection for software is gradually being put on the agenda, patent law is a new trend in the country in recent years, appearing in large software. U.S. Patent Law 101 states: " all useful, new, with the obviousness of intellectual achievements, whether it is a method, a machine, a product or a combination of all substances, are likely to get a patent law protected by U.S. patent law created by man everything under the sun "TRIPS Agreement Article 27:." any invention are entitled to all the technology in the field of patent protection, " but also for patent protection for computer software provides a space. Although China's patent law does not exclude the protection of computer software, but due to some provisions of patent protection as well as our own shortcomings patent law, patent protection of software is still difficult to exist in our country, as follows:

The first is the patent law "patentability" restrictions for computer software is obviously too narrow, some software is difficult to prove their practical novelty, creativity. Category and now, not a combination of software and hardware is often regarded as the mathematical methods or associated with mathematical algorithms, it is often attributed to the rule can not be patentable methods for mental activities.

Followed by computer software as it involves very complicated invention patent examiners to review a long time, is not conducive to the software patent protection. The fast pace of software updates, huge production capacity, and cumbersome application process generally takes two to three years to complete, so it is likely the patent is not approved, the software already approaching the end of life embarrassing situation, when the software product is likely to have been out of the market .

The third is the pre- open system of patent law. Patent law requires that patents be disclosed in advance, the openness of the "ordinary skill in the art to make the same subject." However, compared with the usual invention to create a computer program open to the harm suffered far greater. Because copying computer software is very easy, once the pre- open, very difficult to protect the rights of its own proprietary rights .

Fourth, technical requirements, quality inspector difficult to reach. The fast pace of software updates, a huge amount of software newborn, while involved in various fields of computer software, requiring the inspector has excellent expertise in computer software, in practice it is difficult to achieve.

The fifth is a long period of patent protection is not conducive to software upgrades and updates, in practice, is also prone to being protected software has been out of the market, thus further protecting its long obviously unreasonable

In addition, the " Trade Secrets Law" protection of computer software, there are some problems, some of our computer software may use trade secret law to protect its intellectual property, but it can also occur some problems : trade secrets do not have exclusive rights, can not get the right to exclude others who take security measures through legitimate means of information protection with its fragility ; in our country, easily lead to the emergence of monopolies, is not conducive to study and follow-up of the software improvements might be made public right of fair use Unduly limit ; difficult and high- cost protection in the international community did not form a unified standard.

\section{Measures of China's computer software intellectual property protection}

For the protection of computer software from a single comprehensive and integrated copyright protection to protect the development is the trend. Theory and practice have shown that the main drawbacks of traditional copyright law to protect that "inadequate", and the main flaw lies in the protection of patent law simply " too much ." So I should not advocate specific legislation, and should establish a comprehensive protection mode protection. That is the core of the copyright law , within the framework of existing patent law as individual chapters fit amendments and supplements to protect computer software, so that the two become coordinated legal system, supplemented trademark, trade secret, not anti- related to the protection of legitimate competition law , contract 
law, so as to establish a multiple, comprehensive protection mode. Specifically as follow:

Computer software should remain with the copyright law to protect its intellectual property rights protection center, which is the foundation of computer software to improve intellectual property protection;

Make appropriate modifications to existing software protection of patent law in the relevant sections. For example: from the legislation, our response to computer software patents adopts a positive attitude, a clear patent protection, and relaxed review of its patentability to be consistent with the patent power. At the same time, it should be from the novelty, creativity for its strict control to prevent the excessive authority ; shorten review time software patents to protect them better ; patent applications for computer software prescribed special procedure pre- open system can be changed to " prior authorization, after the public ", but if found to infringe on the authority of the earlier rights, should be given more stringent revocation and punishment system to the system of correction ; should also shorten the computer software patent protection period, the law should provide protection for a long time have been some of the software out of the market .

Computer software is often an important manifestation of the country, the company's core technology and competitiveness, in the framework of copyrights and patents is still not sufficient to protect the interests of intellectual property rights associated with computer software, the supplementary protection in other areas is vital. For some brand- effective, reputable software, you can use the trademark to help users identify their source, in conformity with trademark law, you can apply for well-known trademarks ; For those handful of dedicated software developed specifically user, you can use commercial secret law and contract law to protect one of the technical secrets, in addition, no legal basis for some of the new cases appearing in software protection can be adjusted with the anti-Unfair competition Law, in order to compensate for the lack of all kinds of legislation .

\section{Conclusion}

In my point of view, I can't agree the reason in the form of separate legislation to protect computer software that: computer software as a new phenomenon, has its own peculiarities, but its protection also does not go beyond the framework of our existing intellectual property protection is not necessary because a the emergence of a new thing so reckless internal logic inherent in the legal system side issues. We just need to make on a specific system to supplement and modify computer software characteristics fit and make legal departments cooperate with each other to form an integrated, multi- software intellectual property protection system.

\section{References}

[1]RUI Tingxian, The application of computer [M], Shanghai University of Finance and Economics press, Shanghai, 2013.

[2]. LI Yang, Intellectual property rights theory and the frontier problem [M], Law Press, Beijing, 2004.

[3]. WANG Guiguo, International IT legal issues research [M], Fangzheng Press, Beijing, 2003.

[4]. LAI Xiaopeng, Intellectual property law[M], China University of Political Science and Law Press, Beijing, 2008. 